\title{
3D Printing Services: Classification, Supply Chain Implications and Research Agenda
}

\begin{abstract}
Purpose - This study aims to identify and classify the available types of 3D printing services, with the scope of determining the potential implications that such services could have on the supply chains of manufacturing firms and creating a research agenda for future studies.

Design/methodology/approach - The authors review the current literature on the potential supply chain impacts of 3D printing and evaluate the 3D printing services provided by 404 firms in selected European markets.

Findings - Our results show that 3D printing services form a rapidly evolving industry, with new service providers entering the market on a regular basis. Evidence from the European markets investigated suggests that services can be classified into three distinct categories: generative, facilitative and selective services.

Research limitations/implications - This paper represents an attempt to take stock of a fastmoving and potentially paradigm-shifting market. The implications are dynamic as new applications, business models and techniques are continually being developed. Further studies are required to substantiate the findings.

Practical implications - Three categories of 3D printing services that could significantly impact supply chain configurations of the future are proposed. Several issues specific to 3D printing services raised in the research agenda require further scrutiny and substantiation before services can reach their full potential.

Originality/value - This paper provides an overview of the growing $3 \mathrm{D}$ printing services industry, highlighting how the market might change as additive manufacturing technology matures.
\end{abstract}

Keywords - 3D printing, 3D printing services, additive manufacturing, rapid prototyping, supply chains, customization, glocalized production

Paper type - Research paper

\section{Introduction}

Imagine a scenario whereby you have just purchased a new car and would like to replace the existing 'black' cup holder with a 'red' cup holder to match your personal taste. This simple scenario raises important issues in terms of design, make, fit and the associated logistics and supply chains. Immediately, a number of questions are raised. These include: who creates the design for a one-of-a-kind 'red' cup holder, who can manufacture it, who can install it, from where and how do we source raw materials, what does the supply chain structure look like, what are the intellectual property rights issues, what happens if something goes wrong (who is to blame), and how do we control the quality of design, make and fit? Scenarios such as these have led to the development and growth of the 3D printing services industry.

3D printing (also known as additive, digital and rapid manufacturing) refers to not one, but multiple technologies and manufacturing processes that enable users to create a tangible object from a digital three-dimensional model (Hopkinson, et al., 2006; Lipson and Kurman, 2013; Gibson, et al., 2015). Unlike traditional ('subtractive') manufacturing processes, 3D printing technology allows users to build highly complex products from a large variety of materials (e.g. plastic, metal, ceramic, sandstone, resin, bio material and food substances), while demanding little to no retooling from work order to work order, or product to product (Tuck, et al., 2007; 
Conner, et al., 2014; Kietzmann, et al., 2015). This flexibility allows for unparalleled levels of customization, to the point where each printed unit can be an entirely new product, i.e. one of a kind (Petrick and Simpson, 2013; Conner, et al., 2014).

As a result, 3D printing has seen widespread adoption in sectors that predominantly produce small batches of products and/or require customization, such as medicine (Rengier, et al., 2010), aerospace (PwC, 2013) and custom-made consumer goods (Manyika, et al., 2013). Even though 3D printing could potentially make supply chains leaner, more agile, more responsive, more cost effective, more sustainable and overall less wasteful (Hopkinson, et al., 2006; Tuck, et al., 2007; Holmström, et al., 2010; Gebler, et al., 2014; Kietzmann, et al., 2015, Despeisse, et al, 2016), manufacturers are not yet convinced that it can fully replace traditional manufacturing processes, particularly at high production volumes (PwC, 2016). For industry sectors where customization is seldom required and/or cost is a key performance measure, traditional manufacturing technologies will continue to dominate (PwC, 2016). Indeed, as noted by Holweg (2015), Bogers, et al. (2016) and Sasson and Johnson (2016), additive manufacturing is unlikely to replace traditional manufacturing processes, at least in the short and medium term, but will instead complement existing production processes.

Widespread adoption of 3D printing is hindered by a number of decisive factors including high printer acquisition costs, lack of experience with the technology and the technical limitations of 3D printers (Hopkinson, et al., 2006; Berman, 2012; Gibson, et al., 2015; PwC, 2016). Furthermore, successful implementation of 3D printing processes relies on the intersection of two supply chains: the supply chain of a machine and materials vendor and the supply chain of the company intending to purchase the tools that allow them to 3D print products (Mellor, et al., 2014). In this configuration, companies intending to use 3D printing can only do so by purchasing expensive manufacturing equipment from a specialized vendor. This need not necessarily be the case, however. Firms seeking to utilize 3D printing could instead use the services of a $3 \mathrm{D}$ printing services provider. In this way they would substitute a 'committed' relationship with a machine vendor for a flexible and less capital-intensive agreement with the service provider (Lipson and Kurman, 2013; Rayna, et al., 2015).

A variety of on-demand 3D printing services are now emerging, and if this trend continues, they are expected to be major drivers of market growth over the next decade (Canalys, 2014; Manyika, et al., 2013). 3D printing services include all types of services that can transform a customer's chosen 3D model into a physical object with the help of additive manufacturing technology. A typical 3D printing service enables customers to employ a unique combination of design-related and manufacturing-related service components to fulfil their vision (Rayna, et al., 2015). Thus they can try out a range of 3D printing techniques and their related products without demanding major capital investments (or strategic-level decisions). In other words, 3D printing services fill a demand gap until the technology becomes mature, easy to use and cheap enough for companies and even consumers to adopt it on a large scale (Gartner, 2015). Another possible outcome of the growth in the $3 \mathrm{D}$ printing service industry is that it may eliminate the need for companies to purchase their own (quickly outdated) printers altogether.

By using such a service, enterprises could potentially reap the aforementioned supply chain benefits (Tuck, et al., 2007) while simultaneously avoiding the high costs of acquiring 3D printing equipment, training staff and scheduling maintenance (Hopkinson, et al., 2006; Gibson, et al., 2015). The simplicity and mutual benefit of the relationship between service providers and manufacturers prompted a positive market response, with 3D printing service providers emerging around the world as early as 2007 (Lipson and Kurman, 2013; Rayna, et al., 2015). 
Academic response has been comparatively limited, with only a few scholars addressing the implications of additive manufacturing for services (Lipson and Kurman, 2013; Holmström and Partanen, 2014; Rayna, et al., 2015; Troxler and van Woensel, 2016). The vast majority of publications to date have focused almost exclusively on the technological intricacies of 3D printing. For example, at the time of writing, of the over 2,400 ScienceDirect articles discussing $3 \mathrm{D}$ printing from the past 10 years, only 12 address (to varying degrees) its potential impact on supply chains. Owing to the increasing importance of this industry, there is now a clear imperative for further research, not least to clarify how 3D printing services could complement, replace or even create entirely new supply chains.

To address this research gap, this study identifies the available types of 3D printing services, classifies the services currently being offered, and proposes a research agenda for future studies on how 3D printing services will impact supply chains. This paper first provides an overview of the 3D printing services-related literature. This is followed by a cross-sectional market analysis (as of December 2015) of on-demand 3D printing services in Europe, specifically in the DACH (Germany, Austria and Switzerland) and Benelux (Belgium, the Netherlands and Luxembourg) markets. Based on these findings, an extended theoretical framework for the 3D printing services industry is proposed. The final section presents a research agenda for future work.

The European market for 3D printing services is second only to the North American market in terms of the number of industrial 3D printing machines being used (Richter, 2014). Europe has also been the launching pad for many successful 3D printing services. More specifically, the DACH and Benelux markets have become the launching pad of some of the most impactful 3D printing companies in the worldwide 3D printing industry, including both service providers like Shapeways (shapeways.com), Materialise (i.materialise.com) and 3D Hubs (3dhubs.com), as well as major producers of 3D printing technology such as EOS (eos.info), Voxeljet (voxeljet.com) and Ultimaker (ultimaker.com).

\section{D printing services supply chain implications}

Since the invention of Selective Laser Sintering printers in the 1980s (Lipson and Kurman, 2013), additive manufacturing technology has undergone multiple phases of adoption, ranging from rapid prototyping in the early 1990s, to rapid tooling in the late 1990s and rapid (direct) manufacturing in the late 2000s (Rayna and Striukova, 2016). Several authors anticipate that the next adoption phase will involve integrating consumers into the design and manufacturing process, possibly to the point where they can print finished products, as well as spare parts, at home (Berman, 2012; Lipson and Kurman, 2013; Fox, 2014). This scenario is described as home fabrication (Rayna and Striukova, 2016). Industry forecasts as to when widespread adoption of 3D printing (particularly consumer 3D printing) will take place are, however, repeatedly being pushed into the future (see for example Gartner, 2010 compared to Gartner, 2014 and Gartner, 2015). Currently, commercial use of the technology is primarily restricted to basic prototyping, rather than large-scale rapid manufacturing (Gress and Kalafsky, 2015; PwC, 2016). It is, indeed, questionable whether home fabrication will be a realistic proposition for most consumers.

Instead, local fabrication, which can be viewed as an intermediary or parallel phase, could prove to be more feasible. Here, on-demand 3D printing service providers carry out a range of 3D printing-related services from design through to manufacturing, thereby leveraging the versatile manufacturing capabilities of direct manufacturing outside of firms' and consumers' homes (Rayna and Striukova, 2016). Online platforms for 3D printing services can for example serve 
as design marketplaces, printing services, printing marketplaces and crowdsourcing platforms (Rayna, et al., 2015). 3D printing services can therefore generally be understood as a group of services that provide a unique combination of design-related and manufacturing-related activities to their customers (Rayna, et al., 2015), with the intention of facilitating the customer's journey from concept (or 3D model) to a 3D printed object.

It is important to distinguish between $3 \mathrm{D}$ printing services and services related to the $3 \mathrm{D}$ printing process. For the purposes of this study, a service may only be referred to as a 3D printing service if it includes both a design-related and manufacturing-related component. An online 3D model sharing platform such as Thingiverse (thingiverse.com) would thus not be considered a 3D printing service, as it does not facilitate the actual 3D printing of the model (the manufacturing side of the supply chain). Services that do not incorporate additive manufacturing into their supply chains would more appropriately be classified as computeraided design services. While standalone design services can be subsequently coupled with a 3D printing service (in the form of the facilitative services described later on in the article), they should not be regarded as 3D printing services themselves. Similarly, the sale of 3D printing machines and materials, training and consultancy services and device rental or maintenance services are considered as 'auxiliary' to the 3D printing process.

Although few studies have focused on $3 \mathrm{D}$ printing services, one can nonetheless predict to a certain extent the impact that such services could have on firms' supply chains. As noted by Berman, (2012), the nature of additive manufacturing technology enables companies to completely outsource both design and manufacturing to a 3D printing service provider such as Shapeways (shapeways.com), reaping the benefits of 3D printing without suffering from drawbacks such as high machine acquisition costs and the risk of technological obsolescence. As a result, and as presented in Table 1, companies can benefit from the positive contributions that $3 \mathrm{D}$ printing can make to supply chains and the overall efficiency of manufacturing firms while mitigating the risks and issues associated with the technology by transferring these to the service provider.

\begin{tabular}{|l|l|l|}
\hline Factor & Key References & Description \\
\hline Supply Chain Costs & $\begin{array}{l}\text { Hopkinson, et al. (2006); } \\
\text { Lipson and Kurman } \\
\text { (2013); Gibson, et al. } \\
\text { Setup Costs }\end{array}$ & $\begin{array}{l}\text { Using a service instead of in-house } \\
\text { manufacturing facilities eliminates costs } \\
\text { associated with the acquisition of equipment } \\
\text { and trained staff, as well as costs related to the } \\
\text { maintenance and retooling of printers and } \\
\text { printing facilities. }\end{array}$ \\
\hline Unit Costs & $\begin{array}{l}\text { Hopkinson and Dickens } \\
(2003) ; \text { Hopkinson, et al. } \\
(2006) ; \text { Atzeni and Salmi } \\
\text { (2012); Gebler, et al. } \\
\text { (2014); Gibson, et al. } \\
\text { (2015); Baumers, et al. } \\
\text { (2016); Sasson and } \\
\text { Johnson (2016); Thomas } \\
\text { (2016) }\end{array}$ & $\begin{array}{l}\text { Additive manufacturing can reduce costs per } \\
\text { unit in small production batches of customized } \\
\text { or complex products in comparison to } \\
\text { traditional manufacturing methods. Services } \\
\text { can reduce costs even further by maximizing } \\
\text { printer and build chamber utilization rates, } \\
\text { operating several machines with limited staff } \\
\text { and recycling support material. }\end{array}$ \\
\hline
\end{tabular}




\begin{tabular}{|c|c|c|}
\hline Error Costs & $\begin{array}{l}\text { Hopkinson, et al. (2006); } \\
\text { Gibson, et al. (2015) }\end{array}$ & $\begin{array}{l}\text { Additional costs and corresponding risks that } \\
\text { may result from errors or interruptions in } \\
\text { printing are transferred to the service provider. }\end{array}$ \\
\hline $\begin{array}{l}\text { Inventory and } \\
\text { Logistics Costs }\end{array}$ & $\begin{array}{l}\text { Holmström, et al. (2010); } \\
\text { Huang, et al. (2013); Mohr } \\
\text { and Khan (2015) }\end{array}$ & $\begin{array}{l}\text { By outsourcing manufacturing, companies can } \\
\text { reduce inventory to a minimum, printing } \\
\text { products and replacement parts solely on } \\
\text { demand. Using local printing facilities further } \\
\text { reduces the costs associated with the } \\
\text { transportation and handling of products. }\end{array}$ \\
\hline \multicolumn{3}{|c|}{ Supply Chain Flexibility } \\
\hline Volume & $\begin{array}{l}\text { Hopkinson, et al. (2006); } \\
\text { Holmström, et al. (2010); } \\
\text { Conner, et al. (2014); } \\
\text { Sasson and Johnson (2016) }\end{array}$ & $\begin{array}{l}\text { A network of 3D printing services would allow } \\
\text { companies to alternate between low and high } \\
\text { volumes of production, depending on demand. }\end{array}$ \\
\hline Capacity & $\begin{array}{l}\text { Holmström, et al. (2010); } \\
\text { Gibson, et al. (2015) }\end{array}$ & $\begin{array}{l}\text { While owning printers limits companies to the } \\
\text { specifications of the devices (e.g. in terms of } \\
\text { build chamber size, printing speed, and } \\
\text { resolution), suitable services can generally be } \\
\text { found with any specifications (within the } \\
\text { bounds of what is technologically feasible). }\end{array}$ \\
\hline Specialization & $\begin{array}{l}\text { Lipson and Kurman } \\
\text { (2013); Mellor, et al. } \\
\text { (2014); Gress and Kalafsky } \\
\text { (2015) }\end{array}$ & $\begin{array}{l}\text { Firms can choose to employ highly specialized } \\
\text { services that for example have repurposed } \\
\text { printers to fulfil the needs of specific sectors } \\
\text { (e.g. dentistry or aerospace). }\end{array}$ \\
\hline Location & $\begin{array}{l}\text { Holmström, et al. (2010); } \\
\text { Gress and Kalafsky (2015); } \\
\text { Petrick and Simpson } \\
\text { (2013) }\end{array}$ & $\begin{array}{l}\text { Local service providers are able to manufacture } \\
\text { products closer to the point of sale or } \\
\text { consumption, in a format that accounts for the } \\
\text { tastes and expectations of the market. }\end{array}$ \\
\hline \multicolumn{3}{|c|}{ Supply Chain Output } \\
\hline $\begin{array}{l}\text { Product } \\
\text { Customization }\end{array}$ & $\begin{array}{l}\text { Hopkinson, et al. (2006); } \\
\text { Berman (2012); Conner, et } \\
\text { al. (2014); Kietzmann, et } \\
\text { al. (2015) }\end{array}$ & $\begin{array}{l}\text { Alongside printing customized products, } \\
\text { service providers can also offer further } \\
\text { customization options for customers if the } \\
\text { contractor grants them the ability to e.g. alter } \\
\text { the 3D model or use unusual combinations of } \\
\text { materials. }\end{array}$ \\
\hline $\begin{array}{l}\text { Product } \\
\text { Complexity }\end{array}$ & $\begin{array}{l}\text { Hopkinson, et al. (2006); } \\
\text { Conner, et al. (2014) }\end{array}$ & $\begin{array}{l}\text { Unlike traditional manufacturing processes, 3D } \\
\text { printing allows companies to make products } \\
\text { significantly more complex, without } \\
\text { generating additional complexity-dependent } \\
\text { costs beyond material costs. }\end{array}$ \\
\hline Product Agility & $\begin{array}{l}\text { Holmström, et al. (2010); } \\
\text { Lipson and Kurman } \\
\text { (2013); Conner, et al. } \\
\text { (2014) }\end{array}$ & $\begin{array}{l}\text { Companies can respond quickly to marketplace } \\
\text { changes, dynamically altering product } \\
\text { portfolios and switching service providers as } \\
\text { markets shift. }\end{array}$ \\
\hline
\end{tabular}




\begin{tabular}{|l|l|l|}
\hline $\begin{array}{l}\text { Time To } \\
\text { Market }\end{array}$ & $\begin{array}{l}\text { Holmström, et al. (2010); } \\
\text { Lipson and Kurman (2013) }\end{array}$ & $\begin{array}{l}\text { By outsourcing manufacturing, companies can } \\
\text { focus on core competencies such as product } \\
\text { design exclusively and shorten the lead time to } \\
\text { market for new products. }\end{array}$ \\
\hline Sustainability & $\begin{array}{l}\text { Berman (2012); Huang, et } \\
\text { al. (2013); Gebler, et al. } \\
\text { (2014); Gress and Kalafsky } \\
\text { (2015); Mohr and Khan } \\
\text { (2015); Despeisse, et al. } \\
\text { (2016) }\end{array}$ & $\begin{array}{l}\text { Combining the resource-efficient nature of } \\
\text { additive manufacturing technology with the } \\
\text { ability of services to produce just-in-time and } \\
\text { closeness to the customer will have a } \\
\text { significant positive impact on the } \\
\text { environmental footprint of contractors. }\end{array}$ \\
\hline
\end{tabular}

Table 1: Impact of 3D printing services on manufacturers' supply chains

3D printing services are not a 'one-size-fits-all' solution. The ability of the 3D printing service providers to achieve the positive impact outlined in Table 1 depends largely on the types of services the client chooses to employ and the characteristics and unique position of the client in question, particularly when considering costs. As explained in the additive manufacturing implementation framework of Mellor, et al. (2014), any form of implementation demands a strategic alignment of the business, manufacturing and R\&D strategy. Firms must thus consider strategic, technological, organizational, operational and supply chain factors before deciding whether to utilize 3D printing, regardless of whether it is done through in-house facilities or by subcontracting via 3D printing service providers (Mellor, et al., 2014). While outsourcing 3D printing activities to a service provider eliminates certain risks related to additive manufacturing technology (such as investing in equipment, training and skilled personnel), it still subjects the contracting company to the same types of risks associated with a standard manufacturersupplier relationship (Rao and Goldsby, 2009). There are, furthermore, regulatory and legal vagaries associated with 3D printing (Gress and Kalafsky, 2015; Kietzmann, et al., 2015; Mohr and Khan, 2015), most notably with regard to copyright and the corresponding rights and responsibilities (Rideout, 2011; Doherty, 2012; Weinberg, 2013). As certain branches of 3D printing mature, particularly in medical applications, companies may face additional regulatory constraints and certification requirements that could burden such agreements among service providers and manufacturing firms.

While assessment of company readiness can only be carried out on a case-by-case basis, it is possible to assess the typical service offerings that allow service providers to fulfil the needs of their customers (the manufacturing companies). This can be achieved by analyzing the range of services available. To examine the market in this way, the following sections present a snapshot of 3D printing service providers in European markets, as of December 2015.

\section{D printing services in Europe}

To identify which types of 3D printing services are currently offered to companies and consumers in European markets, the first stage of this research involved creating a comprehensive index of service providers operating in the six countries chosen for the analysis (details on the selection criteria are given below). Although multiple databases of 3D printing firms exist (see for example 3printr.com), desk research quickly revealed that developing a more complex index would be required to fully understand the nuances of the market. As already noted, the very definition of what constitutes a 3D printing service or 3D printing firm varies from author to author (Rayna, et al., 2015; Wohlers Associates, 2015; Troxler and van Woensel, 2016). Most databases and authors furthermore only provide data on the largest 
service providers, such as Shapeways, 3D Hubs and i.materialise, omitting less-known smalland medium-sized service providers. Smaller firms could however play an equal if not overall larger role than the big global players in the supply chains of the future. The long tail analysis of Sasson and Johnson (2016) reveals that small- and medium-sized adopters of additive manufacturing technology could eventually evolve into direct digital manufacturing 'supercenters', significantly impacting global supply chain configurations. All identified service providers, regardless of their size, maturity, or level of success, were therefore included in the data set.

Service provider data was collected by a variety of means: scrutinizing publicly available local and global databases of firms offering 3D printing-related services; using keywords to browse newspaper and business magazine articles; manually identifying company websites using internet search engines; and examining exhibitor lists and portraits from major 3D printing conferences and events that took place within the past ten years. Notable sources of secondary data on each firm included both information made publicly available by the companies themselves and information provided by trustworthy third parties. Further key sources included the company's website, brochures, catalogues, marketing material, press releases, instructional material (including wikis, guides and videos) and recruitment material.

To further improve data accuracy and reduce the influential effect that promotional material could have on the assessment of a company, the data was also compared where possible to third-party sources, including listings and publications of the chambers of commerce, case studies in academic papers, news reports and exhibitor portraits from 3D printing events. Data points that were subject to erroneous interpretation or could not be collected from these sources were confirmed through brief phone conversations with the respective companies. Data collection took place on a country-by-country basis between October and December 2015, starting with the DACH countries (Germany, Austria, Switzerland) in October and the Benelux countries (Belgium, Luxembourg and the Netherlands) in November 2015. The whole data set was verified for the last time on December 31,2015, ensuring that the data most accurately reflects the market situation at the end of the year. Due to the somewhat volatile nature of the market, some of the identified companies will likely have either expanded their range of services or gone out of business altogether by the time of publishing.

Identified companies were assigned to one of four groups, depending on the focus and nature of their business model: consumer 3D printing services, enterprise 3D printing services, 3D printing equipment and material producers, and 3D printing equipment and material distributors. Companies that did not provide services or products in line with one of the four categories (e.g. producers of 3D scanning equipment) were not taken into consideration. Similarly, identified service providers that were not headquartered in one of the six focus markets, or did not generate the majority of their revenue in these markets from 3D printing services or products, were excluded from the final data set.

It is important to note that certain studies and industry reports (see for example Wohlers Associates (2015)) tend to place both consumer (B2C) and enterprise (B2B) 3D printing services in the same group. Troxler and van Woensel (2016) note, however, that a distinction between the two should be maintained, as consumer and enterprise 3D printing services differ greatly in the types of services they offer, their level of maturity, their manufacturing capabilities and in the way they will impact society. The process of building the index of service providers revealed early on that this is indeed the case, with service providers operating in each group clearly following diverging paths of specialization in favor of their respective target 
customers. Companies that provide 3D printing services in line with the previously discussed definition were thus split into consumer and enterprise 3D printing services, depending on which category of customers (B2C or B2B) they primarily target. In cases where the target customer could not be clearly defined, the companies were contacted to ensure their correct categorization.

The final two categories of companies - equipment and material distributors (wholesalers) and equipment and material producers (innovators and developers) - were included in the analysis for the purpose of comparing the overall size and composition of the markets. Well-established networks of producers and distributors for 3D printing equipment (e.g. 3D printers, replacement parts, accessories) and 3D printing material form the foundation of a flourishing market for 3D printing services. The long-term survival and growth of 3D printing services is directly impacted by the ability of equipment and material producers and distributors (who act as suppliers) to match the demand of the service providers. These distributors and producers thus form a crucial pillar of the 3D printing services industry.

Following the successful creation of an index of 558 companies operating in the 3D printing industry of the six targeted countries (see Table 2), the final stage of the desk research involved analyzing the identified 404 firms in the first two columns (105 consumer and 299 enterprise) of $3 \mathrm{D}$ printing service providers. The objective here was to create a universal classification system for 3D printing services. Two additional columns comprised of 111 equipment and material distributors and 43 equipment and material producers were included in Table 2 in order to provide a full picture of the size and composition of each market. Further insights pertaining to each market are discussed in the following section.

\begin{tabular}{|l|c|c|c|c|c|}
\hline Country & $\begin{array}{c}\text { Consumer 3D } \\
\text { Printing } \\
\text { Services }\end{array}$ & $\begin{array}{c}\text { Enterprise 3D } \\
\text { Printing } \\
\text { Services }\end{array}$ & $\begin{array}{c}\text { Equipment } \\
\text { and Material } \\
\text { Distributors }\end{array}$ & $\begin{array}{c}\text { Equipment } \\
\text { and Material } \\
\text { Producers }\end{array}$ & Total \\
\hline Germany & 51 & 151 & 41 & 15 & 258 \\
Austria & 9 & 26 & 8 & 2 & 45 \\
Switzerland & 11 & 35 & 15 & 0 & 61 \\
Luxembourg & 2 & 4 & 2 & 0 & 8 \\
Belgium & 11 & 20 & 10 & 2 & 43 \\
Netherlands & 21 & 63 & 35 & 24 & 143 \\
\hline Total & 105 & 299 & 111 & 43 & 558 \\
\hline
\end{tabular}

Table 2: Number of identified companies operating in the 3D printing industry

\section{Classification of 3D printing services}

The results of the literature review indicate that the 3D printing service supply chain is primarily a combination of design- and manufacturing-related processes. Design processes in this context include all activities that take place between the customer and the 3D printing service provider, with the goal of creating or acquiring the $3 \mathrm{D}$ model that is to be used in printing. Manufacturing processes include all activities that take place subsequently to then transform the chosen model into a physical object. As shown in Figure 1, 3D printing service providers operate in 'build- 
to-order' mode, launching design- and manufacturing-related activities only after a customer has placed an order.

Both business partners and private consumers can choose from one of three distinct service routes, depending on the extent to which they require support in acquiring a $3 \mathrm{D}$ model that is suitable for printing. Although creating a classification system based on the manufacturing capabilities of the identified service providers would be possible, in reality most clients would likely first contemplate how to acquire a suitable 3D model of the desired object before considering materials or manufacturing processes. As a result, each of the three categories of services aims to address the needs of clients with varying degrees of interest in and familiarity with additive manufacturing. This ranges from first-time users to experienced customers with a clear vision of what they would like to have.

The authors have classified and named these as generative services, facilitative services and selective services. Generative (scanning and construction) services include all services that aim to generate a 3D model for the customer before subsequently 3D printing it. In contrast, facilitative (upload and in-store) services focus on the printing process itself, tailoring their services to the needs of customers who already possess a 3D model. The final category of services, selective services, does not emphasize design or manufacturing, but instead offers customers a database from which they can select a 3D model, decide how it will be printed and in some cases even alter the model itself beforehand.

Regardless of which service types a customer chooses, the next stage of the process involves transferring the resulting 3D model to the 3D printing facilities where the printing will take place. The 3D printing service provider manages the transfer process between the source of the 3D model (e.g. local scanning facilities) and the production facilities at which the model will be printed. Manufacturing can either take place internally (as is usually the case for enterprise 3D printing service providers) or externally at the facilities of a third-party subcontractor (often the case for consumer 3D printing service providers). The final stage of the process, distribution, is then usually handled at the manufacturing facility, with packaging taking place internally and transportation being handled by a third-party transportation service such as DHL or TNT. The product is then either directly delivered to the contractor (customer), or - if available - left for pick-up at a retail location of the service provider.

The 3D printing service supply chain can be considered a loop that may be carried out repeatedly, to the point where it may be fully integrated into the larger supply chain of a manufacturer, as highlighted by the open ends illustrated in Figure 1. This simultaneously shows how easily 3D printing services could serve as the starting or end point of a manufacturer's supply chain. A customer could for example trigger the order by requesting to be scanned at a retail location of the service provider, with the purpose of creating a 3D model of themselves. The model can then be used by manufacturers to create a wide range of customized products for the customer, including accessories, clothing and even prosthetics. The reverse is also possible. Returning to the car cup holder example presented at the beginning of the paper, one can also imagine a supply chain configuration in which the customer informs a car manufacturer of their desire to order a customized cup holder. The manufacturer can then send the relevant CAD data to a service provider in the vicinity of the consumer, using the service provider as the end-point of the supply chain.

3D printing service providers generally do not restrict themselves to offering only one of the three categories of services; over half of the identified companies offered a combination. 3D 
printing services for consumers in particular often strive to become local or regional all-round experts in 3D printing over time, offering a unique combination of individual service components. B2B service providers on the other hand generally prefer to focus on improving manufacturing capabilities first and foremost, providing additional services only once a productive critical mass is achieved. The data nonetheless indicates that the market for 3D printing services can be considered homogeneous in terms of the types of services being offered in the market. The opposite is true when considering the configuration of design-related and manufacturing-related services of each service provider, which can differ greatly from service provider to service provider. As noted by Lipson and Kurman (2013: 53), "as powerful tools of design and production become available to everyone, the lines between professional and amateur, buyer and seller, designer and consumer begin to blur". This in turn grants service providers the ability to choose from thousands of possible combinations of activities, to the point where each provider in a market could indeed have a unique configuration. The supply chain is designed to be contractor-centric, offering the ability to dynamically change volumes, timings and processes to meet the needs of contractors over time as markets and demands change.

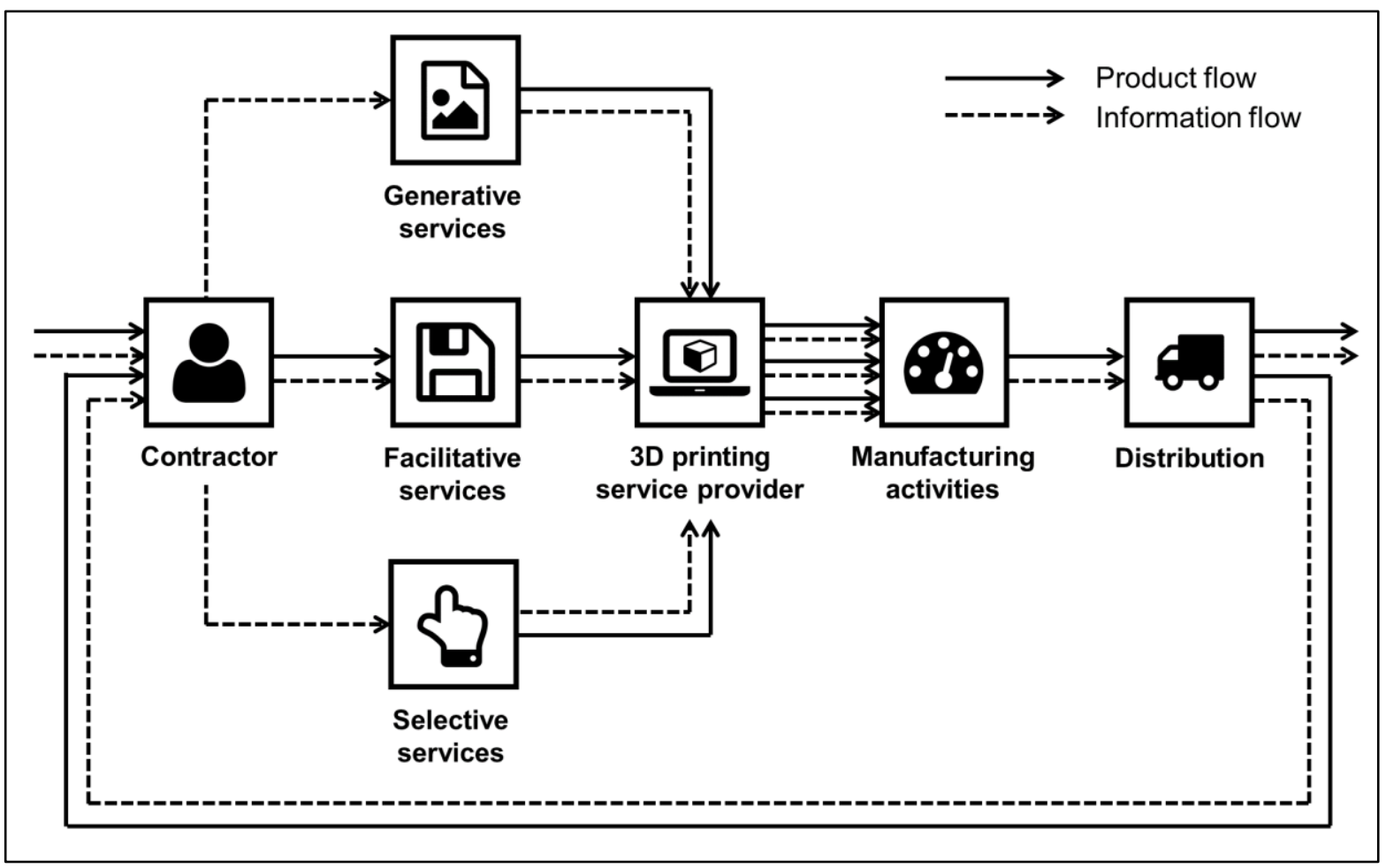

Figure 1: The 3D printing service provider supply chain

Although all of the identified service providers can be considered homogeneous in terms of the types of services they offer there are nonetheless differences amongst the six countries chosen for the analysis. The Netherlands can be considered the most versatile market of the six, having not only a distinctive industry structure, but also the highest density and coverage of firms. The Dutch 3D printing industry is one of the most advanced and most impactful markets for the technology. Leading companies in the worldwide 3D printing services industry that originated in the Netherlands include well-known names such as Shapeways and 3D Hubs. Furthermore, in comparison to all other markets, the Netherlands represents one of the largest bases of 3D printing industry supporters, hosting a large number of art projects, design studios, school initiatives, research institutes, events and conferences dedicated to 3D printing. 
The Belgian 3D printing industry, while smaller than the Dutch market, has also made a noticeable impact. One of the most famous 3D printing companies in the Benelux area is Materialise. The firm was founded in 1990 in Leuven, Belgium, becoming the first provider of $3 \mathrm{D}$ printing services in the region. Materialise is now one of the largest companies operating in the industry worldwide, conducting ground-breaking research in a variety of fields such as biomedical engineering while providing a combination of $3 \mathrm{D}$ printing services to both companies and private customers through its i.materialise platform.

The DACH countries (Germany, Austria, and Switzerland) in contrast focus to a larger extent on enterprise 3D printing services, with nearly $60 \%$ of the identified companies in these markets being classifiable as B2B 3D printing service providers. These companies have a strong manufacturing background, changing the types of services they have been offering for as many as three decades in line with the developments and uses of additive manufacturing technology (Rayna, et al., 2015).

\section{Generative Services}

The first category of services, named as generative services, can be defined as the sum of all types of on-demand 3D printing services that embed activities related to the generation of a 3D model for the customer into their supply chains. As stated by Tuck, et al. (2007), having suitable 3D CAD data can be considered the main requirement for the successful integration of additive manufacturing into the operations of any firm. Generative services consequently act as the only path of entry into additive manufacturing for companies who do not wish to invest in expensive 3D scanning equipment and/or do not have the capability to construct such models internally. Services of this nature therefore not only directly address some of the main barriers to the adoption of the technology, but additionally grant all firms the possibility to enter the growing market for 3D printed goods (even if they have no prior experience).

Generative services can be divided into two distinct subgroups: scanning services and construction services. While scanning services employ 3D scanning equipment (e.g. handheld scanners or $360^{\circ}$ scanning cabins) to create a 3D model, construction services do not require any equipment aside from CAD workstations, which are a staple of every $3 \mathrm{D}$ printing service. Instead, construction services provide customers with a team of designers capable of digitally building a 3D model from scratch based on sketches, images or other forms of documentation provided by the client. Such services can thus support other firms in both digitizing existing products as well as creating new ones, acting as a 'translator' between the physical and digital world. It is important to note, however, that the generative aspect of generative 3D printing services does not necessarily need to be paired with the actual 3D printing of the scanned model. 3D scanning and digital construction/design services that solely create but do not subsequently 3D print a model, while excluded from the data set used in this study, could indeed also be offered as a standalone service. Decoupling the digitalization process in this manner may become necessary in the future, as more companies shift towards low-inventory supply chains for spare parts (Holmström, et al., 2010; Christopher and Holweg, 2011; Sasson and Johnson, 2016), demanding more and more standalone digitalization in order to build digital catalogues of spare parts, components and even entire product lines.

Combining the digitization capabilities of generative services with the flexibility of additive manufacturing offers a key benefit: the ability to inject various degrees of customizability into the manufacturing process (Conner, et al., 2014). Customization is widely considered to be one of the core benefits of 3D printed products (Hopkinson, et al., 2006; Berman, 2012; Lipson and 
Kurman, 2013; Kietzmann, et al., 2015). The supply chain that runs between the contracting manufacturer, service provider and consumer offers two configurations in which customization becomes possible. Consumers interested in customized, personalized products such as clothing, figurines, and prosthetics could for example request to be scanned at one of the service providers' retail locations. The service provider could then send the digital model of the customer to the contracting manufacturer, who can then prepare and ship bespoke products to the consumer in question. The contracting manufacturer may also choose to grant service providers full access to the models in question, enabling them to also handle the printing of the customized product. This in turn would simplify the supply chains of both the contracting firm and the service provider while simultaneously eliminating logistical steps between the two parties altogether (Holmström, et al., 2010).

Although generative services are largely beneficial to firms and consumers, they also bring certain risks. The scenarios described above assume that the client in question desires to have the components and/or products scanned and furthermore is aware that the digitalization takes place. However, this need not necessarily always be the case. As previously experienced in the music industry (Appleyard, 2015), consumers and competitors can employ the exact same services to create and openly share digital copies of their own. This in turn eliminates, or at the very least, severely inhibits the parent firm's ability to profit from their designs. Creating a database of 3D models of products furthermore raises several important questions concerning security and ownership. For this reason, one would expect that services involving the scanning of customers will have limited uptake - at least until appropriate regulations and legal guidelines are put in place. For the time being, consumers can nonetheless choose to have themselves be 3D scanned at their own risk, either for the sake of 3D printing a miniature copy of themselves (a figurine) or for other personal projects.

\section{Facilitative Services}

The second category of identified 3D printing services consists of all services that cater to customers who already possess a digital 3D model they would like to have printed. Unlike generative services, facilitative services do not 'translate' tangible objects into digital ones, but instead do the exact opposite, transforming 3D models into 3D printed objects. Firms offering such services tend to reduce design-related activities to a minimum, focusing instead on effectively facilitating the manufacturing process for the customer. Such services can be considered the natural successor of the rapid prototyping service bureaus that emerged with additive manufacturing technologies in the late 1990s (Rayna and Striukova, 2016).

While focused on manufacturing, facilitative service providers can also offer design-related activities prior to manufacturing. As explained by Gibson, et al. (2015), 3D printing is technologically still far from being as simple to use as its two-dimensional inkjet printing counterpart. A customer's 3D model must often undergo several stages of processing before the 3D printing process can take place. Service providers prefer to reduce this to a minimum, demanding that clients already ensure that their models are ready for printing. Typically this includes ensuring a stable weight distribution, so that the models are watertight and saved in a file format that can be interpreted correctly by the service provider's machines and that the resulting object fits into the build chamber of the service provider's printer. While most firms use email conversations with the client to ensure that the requirements are met, a series of online tools that can dynamically check the model during the ordering process are also now available. Unlike generative services, which require personal contact between the customer and the service provider, facilitative services benefit from the fact that they can decouple design and manufacturing to a large extent. Service providers can, for example, source orders both locally 
and globally, i.e. from online platforms, retail locations, other service providers, as well as

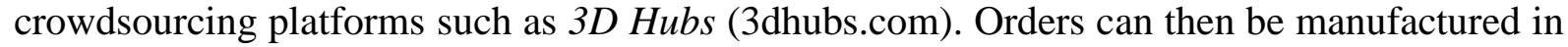
centralized machine parks, in regional distribution centers or even by subcontractors. This in turn allows firms to manufacture products closer to the customer, as well as maximize build chamber and machine utilization across all production facilities, thereby reducing logistical and opportunity costs.

Facilitative services are not limited to additive manufacturing as a service, however. As both companies and consumers become more familiar with 3D printing over time, business models that involve increased levels of customer self-service will proliferate. As an example, German electronics giant Conrad has begun experimenting with a 3D printing self-service area at its Munich store (Conrad, 2016). This business model allows customers the opportunity to lease $3 \mathrm{D}$ printing machines and $\mathrm{CAD}$ workstations, giving them room to experiment. On a larger scale, leasing entire machine parks may become an attractive option for companies interested in manufacturing small batches of products (Sasson and Johnson, 2016). Indeed this approach overcomes one of the oft-cited limitations of 3D printing. Further, more complex distribution models beyond self-service could become economically feasible in the future if demand for facilitative 3D printing services increases. A patent filing of the ecommerce giant Amazon proposes for example a supply chain configuration in which customers' orders may be 3D printed on the go in vehicles equipped with 3D printers (Krassenstein, 2015).

It is important to note that employing additive manufacturing as a service exposes firms to a host of legal risks, the extent of which will remain unclear until the intricacies of copyright laws in 3D printing are resolved (Doherty, 2012; Weinberg, 2013). Almost none of the identified service providers questioned (for example) the origin of the contractor's 3D model or the intended use of the resulting object. Scenarios such as these could potentially lead to future legal action against the service provider. Whether it is financially viable in the long run for facilitative service providers to offer 3D printing services in this manner remains to be seen, particularly when considering that the 3D printing machines available on the market today may no longer be able to match the more competitive unit prices of the equipment that will be available in five, ten or twenty years from now. Technological obsolescence is without doubt the major risk facilitative service providers face.

\section{Selective Services}

The final type of 3D printing services, selective services, can be considered the middle road between its generative and facilitative counterparts. Selective service providers offer customers who do not possess a 3D model the opportunity to select, customize and print a model from their databases. Services of this type can be considered the most accessible of the three types, demanding virtually no understanding of the 3D printing process from the client. Placing an order for a 3D printed product in this manner can be for example as straightforward as selecting a chair at a furniture retailer. In their simplest form, selective services only offer basic choices in terms of the color, material or size of the resulting object. More advanced selective services such as ubimake (ubimake.com) on the other hand even offer customers the opportunity to edit 3D models 'on the go' in a virtual workbench prior to placing their order.

Although only a handful of the identified service providers chose to offer selective services, such services could potentially play an important role in the supply chains of the future. By building digital archives and creating virtual catalogues for spare parts and goods that are out of production, these companies are able to generate profit from outdated and obsolete designs. This in turn reduces the need to hold inventories, as well as eliminates the logistical challenges 
and associated costs (Holmström and Partanen, 2014). A business model to support this approach involves manufacturing firms establishing licensing agreements with selective service providers, allowing them to fully manage the manufacturer's component database in exchange for a share of the profit made from 3D printing and selling the ordered components. This would result in a mutually beneficial situation for both companies, as well as increase customer choice. This is particularly beneficial if the original producer of the product has gone out of business and/or no longer offers that component. Manufacturing firms could furthermore form partnerships with selective service providers in multiple countries, eliminating the need to operate regional distribution centers for such components in the respective markets (Holmström and Partanen, 2014).

Selective service providers could additionally prove impactful on the supply chains of design agencies. Such studios could for example choose to completely outsource manufacturing to a selective service provider, allowing the firm in question to shift its focus towards designing products. A partnership between a design agency and selective service provider can provide clear cost benefits, eliminating additional warehousing and distribution costs that would otherwise occur. Selective services thus grant partners the ability to perfectly match the number of products produced with the number of products sold, dynamically adjusting volumes according to the success of specific designs. The separation of manufacturing from design in this manner moreover supports and grants market access to smaller, less known design studios and freelance designers that would otherwise struggle to bring products to the market, particularly to foreign markets. Selective services with manufacturing facilities in a broad range of countries could eventually even become international design marketplaces that can globally source designs while producing or selling them locally in a format that suits the needs and expectations of the respective customer (i.e. glocalization).

As is the case with generative and facilitative services, selective services also face a number of challenges. A partnership between a manufacturer or designer and selective services provider can only succeed if the 3D printing partner is able to provide the secure infrastructure and insurances that are required to protect the intellectual property of the contracting firm. Data breaches and reverse-engineering by third parties pose a great threat to the business models and long-term capitalization capabilities of both manufacturers and service providers. This is currently a largely unresolved but very important issue and highlights how legislation is failing to keep pace with advances in technology.

\section{Discussion and research agenda}

The study findings suggest that 3D printing services will have a substantial impact on the supply chains and business scenarios of the future. As indicated by the high number of consumer 3D printing service providers, enterprise 3D printing service providers, 3D printing equipment and material distributors and equipment and material producers identified in Table 2, the European 3D printing industry has now successfully entered the phase of local fabrication discussed in Rayna \& Striukova's (2016) review. While still in the early stages of development, the 3D printing services sector has already become home to over 400 service providers in the DACH and Benelux markets. These service providers, while small in number, could have a significant impact on the adoption and dispersion of 3D printing technology. This could be achieved by offering firms - regardless of their experience with additive manufacturing - the opportunity to enter the market for 3D printed goods with limited capital outlay, while providing private customers with the customized products they seek. Thus, 3D printing services may complement, replace or even create entirely new supply configurations, offering unprecedented 
flexibility in terms of production volume, production location, product customization and product complexity.

In reality, 3D printing services have not yet achieved their full potential. Although established service providers such as $3 D \mathrm{Hubs}$, Materialise and Shapeways have developed significantly over the past decade and now offer a broad range of services with a global reach, smaller service providers have yet to achieve comparable results. The majority of the 404 service providers identified operated on a very small scale, fulfilling only a comparatively low number of orders for the local or regional population, rarely maximizing build chamber utilization rates. Enterprise 3D printing service providers have seen steady growth throughout the years, predominantly owing to their ability to manufacture in centralized low-cost locations while shipping to firms and consumer 3D printing service providers throughout the world. Consumer 3D printing firms have, instead, resorted to comparatively higher degrees of specialization. Many prefer to offer either niche manufacturing capabilities via online platforms to a large market (see for example MeltWerk at meltwerk.com) or alternatively strive to become a local all-round expert in 3D printing services, machines and materials (see for example MrMake at mrmake.de). The market for different types of 3D printing services has, however, not yet stabilized, with frequent market entrances and exits.

The study findings indicate that while market structures and players may change over time, 3D printing services can be separated into the three distinct categories of generative, facilitative and selective services. This classification system, while simple, establishes a framework for supply chain-related discussions on 3D printing services. The modular supply chain model (see Figure 1) could, for example, be extended to analyse the supply chains of specific 3D printing service models (e.g. the supply chain of a service provider that produces custom car cup holders in partnership with local car dealerships) or to discuss questions pertaining to all service types (e.g. to assess how service providers can configure their supply chains to maximize build chamber utilization across all manufacturing locations).

Consistent with Hjort et al.'s (2013: 858) assertion that 'one size fits all is no longer valid' or indeed desired by many of today's customers, the variety of service providers suggest that 3D printing services may evolve into highly complex systems of design-related and manufacturingrelated processes, to the point where each service provider in a market may indeed have a unique configuration. Our development of an initial universal classification system and supply chain framework for 3D printing services mitigates potential ambiguities and inaccuracies in future research. The proposed classification system could therefore serve as a first high-level step in building a modular supply chain framework for 3D printing services.

To support the development of the framework and further explore the possible impact of 3D printing services on the supply chains of the future, Table 3 provides an overview of what the authors believe to be the key SCM-focused challenges currently facing the industry and the research community. These have been conveniently classified into supply chain strategy, structures and operations. From this information the authors have developed a list of specific questions and issues that warrant further investigation, organized according to three major supply chain management challenges (supply chain strategies, structure and operations). Examples of each of these challenges are provided below.

At a strategic and structural level, supply chains in future will need to be redesigned to accommodate the increased use of 3D printing services. Various industries have already experienced similar supply chain reconfigurations and strategic challenges. These include 
online shopping in the retail sector (e.g. food and clothing), customized vehicles in the automotive sector and 'power by the hour' in the aerospace sector (Baines, et. al 2012; Baines and Lightfoot, 2014; Pawar, et al; 2009). The new challenges 3D printing poses will require for example ensuring that sufficient labor, technological, as well as financial resources are deployed to secure the required raw materials, meet variable customer demand, minimize disturbances and comply with the required commercial, safety and quality standards.

As the 3D printing services market matures, especially in a consumer-related context, wellestablished global players from sectors such as retail, logistics and/or e-commerce and especially those with advanced cloud computing capabilities will likely enter the market, which could adversely affect small service providers (Armbrust, et al, 2010). An example of this is large retail firms such as Amazon and Media Markt exhibiting early interest in offering 3D printing services on a big scale (Krassenstein, 2015; Media Markt, 2016). Small firms could potentially respond by forming local networks and alliances, thus ensuring they remain competitive and capable of delivering local on-demand 3D printing services. This in turn would allow service providers to maximize build chamber utilization and printing rates across entire markets, leading to manufacturing cost efficiencies.

In terms of supply chain operations, some parallels can be drawn between the developments in 3D printing and those of pharmaceutical drug discovery and development pipeline supply chains. This is especially true in the case of pre-clinical and clinical supply chains where volumes are low but variety, unit cost, level of risk, complexity and the degree of uncertainty are high (Huq, et al., 2016). During pre-clinical and clinical trial periods, clear supply chain strategies, structures and processes to attain the level of robust and resilient systems demanded by commercial supply chains are difficult to establish. Relatedly, in the foreseeable future, 3D printing services supply chains are likely to go through similar phases, as seen in the early parts of drug discovery and developments in the pharmaceutical sector. In addition to these three major supply chain challenges, the authors have noted associated legal and consumer-related considerations. These are also included in Table 3. 
○ What impact will 3D printing services have on global supply chains? Can complexity and risk be reduced?

- Will a large dynamic network of 3D printing service providers around the world emerge? How will this affect supply chain structure and configuration?

- How should 3D printing service providers position manufacturing facilities (i.e. as regional supercenters or local facilities close to end-users)?

- To what extent should service providers be integrated in the supply chains of their contractors? How can supply chain systems and processes be streamlined between the partners?

- Which pricing strategies should each stakeholder in a supply chain develop to maximize profitability and influence end-user demand?

\section{Supply Chain Structure}

- How can structures and processes between different supply chain stakeholders for each type of 3D printing services be aligned?

- How can network complexity be managed, especially considering low volume, high variety and low demand visibility etc. for different $3 \mathrm{D}$ printing contexts?

- How can resilient and sustainable quality systems and processes be built within the context of extended supply chain structure for each type of service provision?

$\circ$ What types of potential uncertainties and disturbances are likely to arise for different 3D printing scenarios and how can these be alleviated?

- How should risk and revenue be shared between the contractors, service providers and other supply chain partners?

\section{Supply Chain Operations}

○ What type and amount of inventory should be held and where should it be held in the pipeline?

$\circ$ Which inventory management system (push or pull) is most viable for each type of $3 \mathrm{D}$ printing service?

- What kind of inventory planning, scheduling and controlling approaches are most suitable for each type of 3D printing service?

- What type of warehousing and distribution network capability (own account, 3PL etc.) is required for each type of 3D printing service?

$\circ$ What type of sourcing (single vs multiple; local vs global) strategies should be adopted? What type of relationship is most appropriate for the various $3 \mathrm{D}$ printing services?

\section{Legal and Consumer Considerations}

- Who owns the 3D model data that is generated or processed by the service provider?

$\circ$ What are the implications of copyright infringement for the respective supply chain partners? How can data security issues be satisfactorily addressed? 
- What types of 3D printed products and services are most popular with consumers? How is this likely to develop over time?

- How important are environmental issues to 3D printing service customers? Can customer returns be handled in a sustainable manner?

- Are existing service performance measurement models and management systems applicable for 3D printing services or are new ones needed? What service quality models/frameworks are most appropriate for 3D printing services?

Table 3: A research agenda for 3D printing services

As indicated in the literature review, many industries are experiencing major reconfigurations of supply chains through increased customer demands (Bogers, et al., 2016; Christopher and Holweg, 2011; Garnter 2014; Holmström and Partnane, 2014; PwC, 2016). 3D printing services still have a long way to go before they will succeed in providing the supply chain benefits discussed in the literature review to a mass market of firms and consumers. However, the evolution and developments in 3D printing over the last couple of decades have outpaced relative developments in supply chain configuration structures and strategy. This is evidenced by the imbalance between the number of technology-focused 3D printing papers and supply chain and general management focused ones (2,400 vs. 12 as outlined above).

As the demand for 3D printed products increases, activities will move from relatively inefficient one-of-a-kind production towards more automated approaches. Currently, flexibility and agility across the supply chain are variable, as these attributes are dependent on their respective supply chain networks (access to raw materials inventory, distribution company vehicle fleets, etc.). As is the case with more mature industries, quality and responsiveness will become key competitive issues. Responsiveness to customer requirements is essentially dependent on the front-end capability and the experience of the 3D printing service provider, underpinned by a stable and resilient supply chain. Much of the industry growth to date has been experienced in unregulated consumer goods, where individuality is one of the most important requirements; however, when the 3D printing industry makes serious inroads into regulated industries such as aerospace, pharmaceutical and medical sectors, then the challenges are likely to be entirely different. The key challenges ahead for the 3D printing services industry will revolve around how to build resilient, flexible, supply chain processes to cater for increased demand.

Copyright and the legal ambiguities associated with 3D printed products furthermore continue to pose major challenges, particularly if governments decide to handle these legal intricacies on an individual case-by-case or country-by-country basis (Troxler and van Woensel, 2016; Weinberg, 2013). Nonetheless, as more firms and markets begin offering 3D printing services, further development towards universal standards, certifications and/or industry guidelines for additive manufacturing as a service would certainly be warranted.

In summary, due to inherent limitations, 3D printing to date is still primarily confined to prototypes, scale models, one-of-a-kind products and to a limited extent short production runs (Holweg, 2015). However, the acceptance of 3D printing is slowly gaining momentum. Over the next decade and beyond, the demand for 3D printing services could potentially shift to batch and high-volume manufacture. As with the technology upon which it is based, the $3 \mathrm{D}$ printing services industry is dynamic, with many opportunities and challenges ahead, making it an apt illustration of managing supply chains in times of turbulence (Christopher and Holweg, 2011). 
It is therefore important for future research initiatives to build upon the findings presented in this study. A substantiation and ranking of the supply chain-related issues associated with 3D printing services identified in the research agenda is one area for further research. The key challenge will be to determine not only how the market for 3D printing services will change and develop over time, but more importantly, what this means for the resulting logistics and supply chain configuration strategies, structures and operations.

Acknowledgement: An earlier version of this paper was presented at the 2016 International Symposium on Logistics held in Kaoshiung, Taiwan, July 2016 and was subsequently revised for publication in IJPDLM. The authors would like to thank Professor Alex Ellinger and the reviewers for their insightful comments and encouragement during the review process.

\section{References}

Armbrust, M., Fox, A., Griffith, R., Joseph, A.D., Katz, R., Konwinski, A., Lee, G., et al. (2010), "A View of Cloud Computing", Communications of the ACM, Vol. 53 No. 4, pp. 5058 .

Appleyard, M. (2015), "Corporate responses to online music piracy: Strategic lessons for the challenge of additive manufacturing”, Business Horizons, Vol. 58 No. 1, pp. 69-76.

Atzeni, E. and Salmi, A. (2012), "Economics of additive manufacturing for end-usable metal parts", The International Journal of Advanced Manufacturing Technology, Vol. 62 No. 9, pp. 1147-1155.

Baines, T., Brown, S., Benedettini, O. and Ball, P. (2012), "Examining green production and its role within the competitive strategy of manufacturers", Journal of Industrial Engineering and Management, Vol. 5, No.1, pp. 53-87 5.

Baines, T. and Lightfoot, H.W. (2014), "Servitization of the manufacturing firm: exploring the operations practices and technologies that deliver advanced services", International Journal of Operations and Production Management, Vol. 34, No. 1, pp. 2-35.

Baumers, M., Dickens, P., Tuck, C. and Hague, R. (2016), "The cost of additive manufacturing: machine productivity, economies of scale and technology-push", Technological Forecasting and Social Change, Vol. 102, pp. 193-201.

Berman, B. (2012), “3-D printing: The new industrial revolution”, Business Horizons, Vol. 55 No. 2, pp. 155-162.

Bogers, M., Hadair, R. and Bilberg, A. (2016), “Additive manufacturing for consumer-centric business models: Implications for supply chains in consumer goods manufacturing", Technological Forecasting and Social Change, Vol. 102, pp. 225-239.

Canalys. (2014), "3D printing market to grow to US\$16.2 billion in 2018", available at: http://www.canalys.com/newsroom/3d-printing-market-grow-us162-billion-2018 (accessed 14 July 2016).

Christopher, M. and Holweg, M. (2011), “'Supply Chain 2.0': managing supply chains in the era of turbulence", International Journal of Physical Distribution \& Logistics Management, Vol. 41 No. 1, pp. 63-82. 
Conner, B.P. (2014), "Making sense of 3-D printing: Creating a map of additive manufacturing products and services", Additive Manufacturing, Vol. 1 No. 4, pp. 64-76.

Conrad. (2016), "Conrad Service: 3D-Printhub", available at:

https://www.conrad.de/de/filialen/filialservice/3d-printhub.html (accessed 14 July 2016).

Despeisse, M., Baumers, M., Brown, P., Charnley, F., Ford, S.J., Garmulewicz, A., Knowles, S., et al. (2016), Unlocking Value for a Circular Economy through 3D Printing: A Research Agenda, Working Paper, Institute for Manufacturing (IfM), Cambridge.

Doherty, D. (2012), "Downloading Infringement: Patent Law as a Roadblock to the $3 \mathrm{~d}$ Printing Revolution”, Harvard Journal of Law \& Technology, Vol. 26 No. 1, pp. 353-373.

Fox, S. (2014), “Third Wave Do-It-Yourself (DIY): Potential for prosumption, innovation, and entrepreneurship by local populations in regions without industrial manufacturing infrastructure", Technology in Society, Vol. 39, pp. 18-30.

Gartner. (2010), “2010 Emerging Technologies Hype Cycle is Here”, available at: http://blogs.gartner.com/hypecyclebook/2010/09/07/2010-emerging-technologies-hype-cycleis-here/ (accessed 20 June 2016).

Gartner. (2014), "Gartner Says Consumer 3D Printing Is More Than Five Years Away", available at: http://www.gartner.com/newsroom/id/2825417 (accessed 7 August 2016).

Gartner. (2015), “Gartner's 2015 Hype Cycle for Emerging Technologies Identifies the Computing Innovations That Organizations Should Monitor", available at: http://www.gartner.com/newsroom/id/3114217 (accessed 22 June 2016).

Gebler, M., Schoot Uiterkamp, A.J.M. and Visser, C. (2014), “A global sustainability perspective on 3D printing technologies”, Energy Policy, Vol. 74, pp. 158-167.

Gibson, I., Rosen, D.W. and Stucker, B. (2015), Additive Manufacturing Technologies: 3D Printing, Rapid Prototyping, and Direct Digital Manufacturing, 2nd ed., Springer, New York.

Gress, D.R. and Kalafsky, R.V. (2015), "Geographies of production in 3D: Theoretical and research implications stemming from additive manufacturing", Geoforum, Vol. 60, pp. 43-52.

Hjort, K., Lantz, B., Ericsson, D. and Gattorna, J. (2013), “Customer segmentation based on buying and returning behaviour", International Journal of Physical Distribution \& Logistics Management, Vol. 43 No. 10, pp. 852-865.

Holmström, J. and Partanen, J. (2014), "Digital manufacturing-driven transformations of service supply chains for complex products", Supply Chain Management: An International Journal, Vol. 19 No. 4, pp. 421-430.

Holmström, J., Partanen, J., Tuomi, J. and Walter, M. (2010), "Rapid manufacturing in the spare parts supply chain: alternative approaches to capacity deployment", Journal of Manufacturing Technology Management, Vol. 21 No. 6, pp. 687-697. 
Holweg, M. (2015), “The Limits of 3D Printing”, Harvard Business Review, available at: https://hbr.org/2015/06/the-limits-of-3d-printing (accessed 10 July 2016).

Hopkinson, N. and Dickens, P. (2003), "Analysis of rapid manufacturing - using layer manufacturing processes for production”, Journal of Mechanical Engineering Science, Vol. 217 No. C1, pp. 31-39.

Hopkinson, N., Hague, R.J.M. and Dickens, P.M. (2006), Rapid Manufacturing: An Industrial Revolution for the Digital Age, John Wiley \& Sons.

Huang, S.H., Liu, P., Mokasdar, A. and Hou, L. (2013), "Additive manufacturing and its societal impact: a literature review", The International Journal of Advanced Manufacturing Technology, Vol. 67 No. 5, pp. 1191-1203.

Huq, F., Pawar, K. and Rogers, H. (2016), "Supply Chain Configuration Conundrum: How does the Pharmaceutical Industry Mitigate Disturbance Factors", Production Planning and Control. DOI: 10.1080/09537287.2016.1193911.

Kietzmann, J., Pitt, L. and Berthon, P. (2015), "Disruptions, decisions, and destinations: Enter the age of 3-D printing and additive manufacturing", Business Horizons, Vol. 58 No. 2, pp. 209-215.

Krassenstein, B. (2015), “Amazon Files Patent for Mobile 3D Printing Delivery Trucks", 3DPrint.com, 25 February, available at: https://3dprint.com/46934/amazon-3d-printingpatent/ (accessed 10 June 2016).

Lipson, H. and Kurman, M. (2013), Fabricated: The New World of 3D Printing, 1st ed., Wiley, Indianapolis, IN.

Manyika, J., Chui, M., Bughin, J., Dobbs, R., Bisson, P. and Marrs, A. (2013), Disruptive Technologies: Advances That Will Transform Life, Business and the Global Economy, McKinsey Global Institute.

Media Markt. (2016), "Wir drucken Dein individuelles 3D-Ebenbild | Media Markt", available at: http://www.mediamarkt.de/de/shop/3d-selfie.html (accessed 15 July 2016).

Mellor, S., Hao, L. and Zhang, D. (2014), “Additive manufacturing: A framework for implementation”, International Journal of Production Economics, Vol. 149, pp. 194-201.

Mohr, S. and Khan, O. (2015), "3D Printing and Its Disruptive Impacts on Supply Chains of the Future”, Technology Innovation Management Review, Vol. 5 No. 11.

Pawar, K.S, Beltagui, A. and Riedel, J.C. (2009), "The PSO triangle: Designing product, service and organisation to create value", International Journal of Operations Management, Vol. 29, No. 5, pp 468-493.

Petrick, I.J. and Simpson, T.W. (2013), "3D Printing Disrupts Manufacturing: How Economies of One Create New Rules of Competition", Research-Technology Management, Vol. 56 No. 6, pp. 12-16. 
PwC. (2013), 3D Printing: A Potential Game Changer for Aerospace and Defense, PwC, available at: http://www.pwc.com/us/en/industrial-products/publications/assets/pwc-gainingaltitude-issue-7-3d-printing.pdf.

PwC. (2016), "3D Printing comes of age in US industrial manufacturing”, available at: http://www.pwc.com/us/en/industrial-products/publications/assets/pwc-next-manufacturing3d-printing-comes-of-age.pdf (accessed 15 July 2016).

Rao, S. and Goldsby, T.J. (2009), "Supply chain risks: a review and typology", The International Journal of Logistics Management, Vol. 20 No. 1, pp. 97-123.

Rayna, T. and Striukova, L. (2016), "From rapid prototyping to home fabrication: How 3D printing is changing business model innovation", Technological Forecasting \& Social Change, Vol. 102, pp. 214-224.

Rayna, T., Striukova, L. and Darlington, J. (2015), "Co-creation and user innovation: The role of online 3D printing platforms", Journal of Engineering and Technology Management, pp. 90-102.

Rengier, F. (2010), "3D printing based on imaging data: review of medical applications", International Journal of Computer Assisted Radiology and Surgery, Vol. 5 No. 4, pp. 335341.

Richter, F. (2014), “Chart: 3D Printing”, available at: http://www.statista.com/chart/2754/3dprinting/ (accessed 7 September 2016).

Rideout, B. (2011), "Printing the Impossible Triangle: The Copyright Implications of ThreeDimensional Printing", Journal of Business, Entrepreneurship \& the Law, Vol. 5 No. 1, pp. 161-176.

Sasson, A. and Johnson, J. (2016), "The 3D printing order: variability, supercenters and supply chain reconfigurations", International Journal of Physical Distribution \& Logistics Management, Vol. 46 No. 1, pp. 82-94.

Thomas, D. (2016), "Costs, Benefits, and Adoption of Additive Manufacturing: A Supply Chain Perspective", The International Journal of Advanced Manufacturing Technology, Vol. 85 No. 5, pp. 1857-1876.

Troxler, P. and van Woensel, C. (2016), "How Will Society Adopt 3D Printing?", in van den Berg, B., van der Hof, S. and Kosta, E. (Eds.), 3D Printing: Legal, Philosophical and Economic Dimensions, T.M.C. Asser Press, The Hague, pp. 183-212.

Tuck, C., Hague, R.J.M. and Burns, N.D. (2007), "Rapid manufacturing - impact on supply chain methodologies and practice", International Journal of Services and Operations Management, Vol. 3 No. 1, pp. 1-22.

Weinberg, M. (2013), What's the Deal with Copyright and 3D Printing, Institute for Emerging Innovation (IEI). 